\title{
Synthesis and Characterization of Erythromycin Loaded PLGA and PCL Microspheres: Antimicrobial Application
}

Lamia Bennabi ( $\sim$ lamia.benabi@univ-tiaret.dz )

University of Sidi Bel Abbes

Ilham Abedelemalek

University of Sidi Bel Abbes

Abedelkader Ammari

National Polytechnic School of Oran (ENPO)

Khaldia Sediri

University of Ain Temouchent

Fatima Bennabi

University of Ain Temouchent

Kaddour Guemra

University of Sidi Bel Abbes

Lahcen Belarbi

University of Ain Temouchent

\section{Research Article}

Keywords: Biodegradable polymers, Erythromycin, Microspheres, release kinetics, antibacterial activity, S. aureus strain.

Posted Date: November 22nd, 2021

DOI: https://doi.org/10.21203/rs.3.rs-1097114/v1

License: (1) (i) This work is licensed under a Creative Commons Attribution 4.0 International License.

Read Full License

Version of Record: A version of this preprint was published at Microbial Biosystems on April 22nd, 2022. See the published version at https://doi.org/10.21608/mb.2022.122642.1051. 


\title{
Synthesis and characterization of Erythromycin loaded PLGA and PCL microspheres: Antimicrobial application
}

\author{
Lamia Bennabi $^{\text {a,b }}$, Ilham Abedelemalek ${ }^{\text {a,b }}$, Abedelkader Ammari ${ }^{\text {c,d }}$, Khaldia Sediri ${ }^{\text {e }}$, \\ Fatima Bennabi ${ }^{\text {f }}$, Kaddour Guemra ${ }^{\text {a }}$, Lahcen Belarbi ${ }^{\text {e }}$ \\ a) Laboratory of Organic Chemistry, Physics and Macromolecules (LCOPM), University of \\ Sidi Bel Abbes, Sidi Bel Abbes (Algeria). \\ ${ }^{b)}$ Department of Chemistry, Faculty of Matter Sciences, University of Tiaret, Tiaret (Algeria). \\ ${ }^{c)}$ Laboratory of Micro and Nanophysics (LaMiN), National Polytechnic School of Oran (EN- \\ PO), Oran (Algeria). \\ d) Department of Physics, Faculty of Matter Sciences, University of Tiaret, Tiaret, Algeria. \\ ${ }^{\text {e) }}$ Laboratory of Applied Chemistry (LAC), University of Ain Temouchent, Ain Temouchent \\ (Algeria). \\ ${ }^{\text {f) }}$ Department of Medicine, University of Saad Dahlb, Blida (Algeria).
}

Corresponding author: lamia.bennabi@univ-tiaret.dz (L.Bennabi)

\begin{abstract}
We presents in this work the preparation of several formulations, based on biocompatible biodegradable polymers: polycaprolactone (PCL) and poly(lactic-co-glycolic) acid (PLGA) loaded with Erythromycin (ERYT) antibiotic. These biocompatible materials were used to prepare microspheres with and without immobilized ERYT via simple evaporation method by simple emulsion. The particle size was determined by scanning electron microscopy and the absence of the interaction with ERYT was confirmed via X-ray diffraction and infrared spectroscopy. The release kinetics of ERYT were studied and then, ERYT loaded PCL and PLGA blends microspheres were used for the inhibition of gram-positive S. aureus strain. The microbial activity was carried-out by Agar diffusion disc method. The results show that PCL/PLGA blend and PCL alone inhibited the strain by ERYT present in kinetic aliquots with the complementary effect of the polymers. A numerical model was proposed for modeling the kinetics reported in our study.
\end{abstract}


Keywords: Biodegradable polymers; Erythromycin; Microspheres; release kinetics; antibacterial activity; S. aureus strain.

\section{Introduction}

Recants studies have evidenced that many polymers can be used as antibiotic carriers owing to the possibility of delivering drugs with minimum side effects [1,2]. Among this class of materials, polycaprolactone, polysacharides chitosan, polyethylene glycol (PEG) or the polyesteramides amphiphilic systems, are use because of their reduce toxicity and excellent biocompatibility [3]. On the other hand, the most studied for local delivery of antibiotics against bacterial strains, are poly(lactic-co-glycolic) acid (PLGA) and poly-lactic acid (PLA) $[4,5]$. These polymers were used to encapsulate several antibiotic with several different prolonged dry delivery systems [6]. However, the limited biodegradability and the hydrophobicity are a barrier for the dissolution of the drug at the first hours. In order to overcome this problem, an amphiphilic system is prepared using a water-soluble polymer physically mixed with polycaprolactone (PCL) [7-8]. Therefore, PLGA is the best candidate to achieve a steady formulation that yields a good dissolution of the antibiotic and an effective release [2-9].

PLGA nanoparticles have an excellent biocompatibility, physical stability and an easy processing. The antimicrobial activity is due to the high percentage of amino groups, which interact with the negatively charged bacterial walls. Hence, the morphology of the surface can be modified and the normal structure of microorganisms is disrupted due to the increased membrane permeability [10]. On the other hand, a low alginate gel microspheres was also, designed in another work to encapsulate ciprofloxacin for antimicrobial controlled release and enhanced bactericidal effect against common pathogens useful for chronic diseases [11]. Antibiotic loaded nanoparticles were found to be very effective against pathogens, as reported by a recent study carried out on nanoparticles encapsulating gentamicin [12,13]. This study has reported a $100 \%$ of efficiency without any noticeable interaction between the matrix used and the antibiotic that will affect the intracellular wall of the pathogen model. Thus, the activity of encapsulated gentamicin has not been modified even after precipitation of the nanoparticles. Accordingly, PLGA is very attractive for any bacteria gentamicin sensitive due to its biodegradable, biocompatible and non-immunogenic properties [2,14]. 
The antibiotic erythromycin (ERYT) has a broad antibacterial spectrum thanks to its binding with the subunits ribosomes of the bacteria studied, which results in the inhibition of the peptide bonds formation and protein synthesis in the bacteria [15]. On the other hand, Erythromycin exhibits a bacteriostatic or bactericidal activity. However, an ideal antibiotic delivery system should be non-reactive in the body and lengthy stable as antimicrobial. The stability of ERYT antibiotic studied in different solutions mediums was found to be $\mathrm{pH}$ dependent. The optimal $\mathrm{pH}$ values allowing to preserve the stability of this carrier are in the range of 7 to 8 [16-17-18].

The present study reports on the synthesis of antibiotic loaded microspheres based on an amphiphilic system consisting of PCL and PLGA blends. The physical mixing between PCL and PLGA for synthetizing of microspheres is presumed to yield an excellent chemical and mechanical stability to erythromycin because of the complementary affinities of these polymers (PCL is hydrophobic, while PLGA is hydrophilic). In order to study the erythromycin release for a possible oral application, which has not been reported previously using this system. The microspheres were prepared by simple emulsion via solvent evaporation method. The antimicrobial activity of the polymeric micro-carriers with the immobilize model antibiotic, was studied using gram-positive strain bacteria i.e. Staphylococcus aureus (S. aureus). Commonly, the nanoparticles are used directly to avoid allergic reactions; otherwise, administration of erythromycin may cause various secondary effects such as hives, a mild rash and anaphylactic reactions. To the best of our knowledge, the antibacterial activity of ERYT loaded polymer system against $S$. aureus strain using aliquots withdrawn from ERYT kinetics release over PCL and PLGA microspheres was not reported before.

\section{Materials and methods}

\subsection{Materials}

PCL $(\mathrm{Mw}=42,000)$ and dichloromethane $(\mathrm{DCM})$ were purchased from Sigma-Aldrich. PLGA with a molar ratio D:L of 75:25 and Gelatin, were obtained from Vonia Biomatrials. Bovine skin (B type) emulsifien agents were obtained from Sigma Aldrich. Erythromycin (ERYT) core material was purchased from Fluka chemika.

\subsection{Preparation of immobilized ERYT loaded microspheres}

An aqueous solution of gelatin (1.5\% wt.) was dispersed in $50 \mathrm{ml}$ of DCM containing $1 \mathrm{~g}$ of PCL, using a mechanical stirrer (Heidolfh RZP1) with $1000 \mathrm{rpm}$ for $3 \mathrm{~h}$. The temperature 
was kept constant at $40{ }^{\circ} \mathrm{C}$. Once DMC evaporates, the microspheres were filtered and washed with distilled water three times. After drying, PCL microspheres were collected following the typical procedure reported elsewhere [21]. Table 1 summarizes the formulation of the samples prepared in the present study. The two formulations A0.1 and A0.2 were prepared in order to optimize the morphology. Finally, the A1 and A2 ERYT loaded microspheres were prepared.

\section{- Yield of encapsulation}

$0.1 \mathrm{~g}$ of the microspheres A1 and A2 were dissolved in $100 \mathrm{ml}$ of buffer solution (pH=7.4) and stirred for $24 \mathrm{~h}$. The drug percentage was calculated from the following formulas:

$$
\begin{aligned}
& \text { Encapsulation yield }(\%)=\frac{\text { Total weight of drug in microspheres }}{\text { Theoretical weight of drug in microsphees }} \times 100 \\
& \operatorname{ERYT}(\%)=\frac{\text { Weight of erytro in microspheres }}{\text { Weight of microspheres }} \times 100
\end{aligned}
$$

\section{- Determination of drug content}

ERYT concentration was determined by UV-visible spectrophotometer (UV-1650 Shimadzu) at $620 \mathrm{~nm}$. The $\mathrm{pH}$ was set at 7.4 to preserve the carrier stability.

\subsection{In-vitro release study}

The release rate of microspheres $\mathrm{A} 1$ and $\mathrm{A} 2$, was determined using dissolution testing apparatus; the dissolution tests were performed using $100 \mathrm{ml}$ for microspheres dispersed under stirring (at $400 \mathrm{rpm}$ ) in a basic solution $(\mathrm{pH}=7.4)$. The temperature was kept constant at $37 \pm 0.5^{\circ} \mathrm{C}$. We have used $100 \mathrm{mg}$ for each test and the drug released was determined by UVvisible spectrophotometry.

\subsection{Characterization}

The particle size distribution of A1 and A2 microspheres were determined using an optical microscope Optika 4083.B1) and the mean particles size was calculated by measuring 100 particles. The shape, size and surface nature of the microspheres were analyzed by optical microscopy and by scanning electron microscopy (SEM; COXEM EM-30AX). The X-ray diffraction (XRD) analysis was performed were recorded with the $\mathrm{Cu}-\mathrm{K}_{\alpha}(\lambda=0.15406 \mathrm{~nm})$ radiation, using a Mini-Flex 600 diffractometer in the range of 0: $0.002 \% / 23 \mathrm{sec}: 70^{\circ}$. The Fourier transform infrared transmittance spectra were recorded using an alpha-Bruker ATR spectrometer in the range of $400-4000 \mathrm{~cm}^{-1}$. 


\subsection{Antibacterial activity}

\section{- Solid medium}

The sensitivity of microorganisms to A1 and A2 was determined by the agar diffusion method in solid medium (Mueller-Hinton Broth). Sterile paper discs (Whatman \# 40; $\varnothing=6.0$ $\mathrm{mm}$ ), were soaked with $15 \mu \mathrm{l}$ of the sample taken from the kinetically released ERYT and placed on the surface inoculated by inoculum of $S$. aureus, which was prepared according to a standard ca. 0.5 McFarland (106 to $108 \mathrm{CFU} / \mathrm{mL}$ ). This latter is the final density recommended for susceptibility tests by the "Antibiogram Committee of the French Society of Microbiology, (A.C.F.S.M.) 2014"

The dishes were incubated at $37^{\circ} \mathrm{C}$ for $24 \mathrm{~h}$ and the zones of inhibition were measured. The sensitivity to the different microparticles A1 and A2 was classified by the diameter of the inhibition halos obtained during the release kinetics of the antibiotic. The experiments were carried out and repeated three times (three biological replicates).

\section{- Liquid medium}

$5 \mathrm{ml}$ of sample of kinetics were inoculated with $1000 \mu \mathrm{l}$ of inoculum. After $24 \mathrm{~h}$ of incubation at $37{ }^{\circ} \mathrm{C}$, the optical density of the growths at $620 \mathrm{~nm}$ was measured with an UVvisible spectrophotometer (Shimadzu UV-1650).

\section{Results and discussion}

\subsection{Encapsulation efficiency and particle diameter}

Table 2 summarizes the mean diameter, dispersion values, production yield and encapsulation efficiency of ERYT loaded A1 and A2 microspheres. It is observed that the yield achieved with A1 is low when compared to that of A2 microspheres. This is due to the small amount of PCL, which was insufficient to cover the drug completely [21]. However, the mean diameter size was almost the same when PLGA was introduced due to molecular morphology of PLGA and hydrophobicity of PCL. The other reason is that the particles size increases proportional to the viscosity of the phase dispersed [18].

\subsection{SEM analysis}

The average radius of the microspheres was found to be $\sim 100 \mu \mathrm{m}$ for A1 (Fig. 1 a) and A2 (Fig. 2 b). The SEM micrographs show that A1 and A2 microspheres have different morphologies non-spherical and non-regular with an oval shape, a non-smooth surface is 
noted with porous microspheres based on PCL contrary to PLGA/PCL blends microparticles .We can say that the A2 microparticles obtained have a smooth and spherical surface ,by adding PLGA to formulation A2

\subsection{XRD analysis}

Fig. 2 depicts the XRD patterns of A1, A2 microspheres and the ERYT antibiotic. It is worth mentioning that PCL is a semicrystalline polymer while PLGA is an amorphous one. Therefore, the Bragg reflections observed on the patterns of A1 and A2 were attributed to PCL crystalline phase. On the other hand, it is observed that the crystalline peaks of ERYT are well resolved indicating the presence of a high crystalline material. However, the patterns of A1 and A2 did not exhibits any peaks associated with ERYT suggesting that the drug is in an amorphous phase in A1 and A2 microspheres.

\subsection{FTIR spectrometry}

The infrared spectra were employed to confirm the compatibility of ERYT with polycaprolactone and PLGA blends used to prepare the microspheres. Fig. 3 shows the FTIR spectra of A1, A2 microspheres and the ERYT antibiotic.

The FTIR spectrum of ERYT confirmed the presence of the characteristics peaks at 3200$3334 \mathrm{~cm}^{-1}$ of C-N stretching mode vibration, which is not observed on the spectrum of A2 and A1. This indicate that ERYT was indeed present in the formulations and the good dispersion of active agent. On the other hand, the other bands are observed in both samples A2 and ERYT.

in common with the IR spectrum of A2 and the spectrum of ERYT

The characteristic peak of $\mathrm{C}=\mathrm{O}$ was observed nearby $1722 \mathrm{~cm}^{-1}$ in both spectra of $\mathrm{A} 2$ and A1. The microparticles prepared with different polymers PCL, PLGA shows the good composition used, suggesting there were no reactions between the drug and PCL, PLGA and had a good stability in formulations used.

\subsection{In-vitro release studies}

Fig. 4 depicts the release profiles of ERYT from A0.1, A0.2 and A2 microspheres. The data show that indeed the ERYT is well released from the A2 because the unloaded formulations with antibiotic give a very low release rates for the microparticles alone . in Fig 
4 ,it is observed that PLGA and PCL give an asorption at this wavelength(623nm) of dissolution of ERYT but it is very low by comparing with the formulations loaded with ERYT

It well known that microspheres prepared by single emulsion evaporation method present initial burst effect release due to surface encapsulated substance. In-vitro release of ERYT from A1 and A2 microparticles were compared with the results obtained from dissolution studies. It was found that the dissolution of ERYT increase in a buffer solution at $\mathrm{pH} 7.4$ is favorable since the percentage yield of release is more than $80 \%$ is reached for the two formulations.

At the initial stage, the burst effect related to ERYT from A1 and A2 is very small in all release profiles. This phenomenon was probably due to the low permeability and hydrophobicity of PCL. The penetration of water molecules into the amorphous region is difficult when compared to that of a crystalline phase. At the start of the kinetics, it is noted that the two formulations give a significant rate of release of ERYT $82 \%$ for A2 and $95 \%$ for A1 after $45 \mathrm{~m}$. This is due to the easy dissolution of ERYT, which is contained more in the PLGA than in the PCL. The difference and the dissolution of antibiotic is fast when compared to that of A1 formulation. For this later, the yield reached $96 \%$ after $1500 \mathrm{~min}$. This behavior may be understood if we consider that the surface of contact of the microspheres with the buffer solution is more pronounced to be greater in A2 microspheres (Fig 6).

This property parameter favors the drug delivery systems indicating that the release mechanism is diffusional and not to a degradation of the polymers. The analysis of the data revealed that the kinetics could be modeling according to the following numerical models:

$$
\text { ERYT rate of release }(\%)=R \cdot\left(1-\frac{r}{R} e^{-\tau \cdot t}\right)
$$

where: $R, r$ and $\tau$ are constants. Fig. 5 depicts the fitting curves of the corresponding release profiles. We have found that this model is suitable to describe all the kinetics of ERYT release. Table 3 summarizes the fitting constants for each formulation (PCL, PLGA and ERYT loaded PCL/PLGA microspheres).

\subsection{Antimicrobial activity}




\section{- Solid medium}

Table 4 resumes the diameters of $S$. aureus strain inhibition by the microspheres based on PCL, PLGA and the buffer solution which is used for the kinetics of antibiotic release $(\mathrm{pH}=7.4)$.

The discs were loaded with $15 \mu 1$ from samples Fig8 and the kinetics aliquots of ERYT from A1 and A2. According to the Fig. (9 and 10), in this case we observe, that the greatest amount of release follow the increase of the diameter of inhibition of the S. aureus strain, which is justified by the progressive dissolution of the antibiotic in the buffer solution at $\mathrm{pH}$ 7.4 .

\section{- Liquid medium}

The optical density (OD) of bacterial cultures, indirectly reflecting cellular growth and number of bacteria (viable and dead), was measured by mixing $1000 \mu 1$ of kinetic samples of the release of ERYT by the microparticles with $100 \mu \mathrm{l}$ of microorganism suspension and cultivated for $48 \mathrm{~h}$ at optimal culture conditions $\left(37^{\circ} \mathrm{C}\right)$. OD was measured at the wavelength of $620 \mathrm{~nm}$ for each sample inoculated with the suspension.

Fig. 11 displays the OD values recorded using A1 and A2 microspheres. The two figures show that the kinetic ERYT released by A1 and A2 exhibit a decrease in the OD of the medium. The measured OD after $48 \mathrm{~h}$ are 0.18 and 0.20 for $\mathrm{A} 1$ and $\mathrm{A} 2$, respectively. Accordingly, there is a complementary effect of the matrix (PCL, PCL/PLGA blend) used with ERYT, which has the same inhibitory effect of the strain when it is administered alone, which confirms the results found in the kinetic release and the antibiotic activity in the solid medium. The analysis of the OD data revealed two distinct behaviors. It was found that OD decreases with time (t) from A1 microspheres following a polynomial dependence, which is given by the numerical model:

$$
O D=0.18-6.09 \times t+8.92 \times t^{2}
$$

The OD decreases of about $55 \%$ after $300 \mathrm{~min}$. On the other hand, OD was found to decease with time (t) from A2 much faster following an exponent numerical model given by: 
The OD decreases of about $79 \%$ after only $60 \mathrm{~min}$. Hence, these results show that the inhibition activity using A2 microspheres is much effective when compared to that of A1 microspheres. Fig. 11

\section{Conclusion}

In this work, ERYT loaded microspheres were prepared by simple solvent evaporation using PCL and PLGA polymers, a comparison between the matrices used revealed that the PLGA associated with PCL provides a rapid release of the antibiotic than the other microparticles. The FTIR and XDR analysis confirmed the absence of interaction with ERYT and the matrix. Thus, the microspheres did not retain the active principle.

The release kinetic depicted a good inhibitory antibacterial activity against $S$. aureus. The data showed that OD of the solution containing ERYT inoculated with the bacterial suspension of $S$. aureus experienced a preferential decrease by A1 and A2 after $48 \mathrm{~h}$, which confirms that the formulations prepared give a good delivery of ERYT in the buffer solution at $\mathrm{pH}=7.4$.

The new ERYT delivery system prepared in this study is very attractive for use as an antibiotic carrier in the treatment of infection because the formulations prepared show a synergistic effect with the encapsulation of ERYT for antimicrobial controlled release and enhanced bactericidal effect against common pathogens $S$. aureus.

In the future, these formulations will be carried out in vivo in order to investigate the side effects of such an application for a safer administration of the formulations developed for sensitive people such as the elderly or children.

\section{Acknowledgments}

The authors thank professor El-H. Belarbi from the Laboratory of Synthesis and Catalysis of Ibn-Khaldoun University (Algeria), for providing access to the XRD and UV-visible analysis. The author L. Bennabi which to thank personally professor Abdelkader Dehbi from the Laboratory of Physical Engineering laboratory of Ibn-Khaldoun University for many helpful discussions.

\section{Reference}


[1] F. Esmaeili, M. Hosseini-Nasr, M. Rad-Malekshahi, N. Samadi, F. Atyabi, R. Dinarvand, Preparation and antibacterial activity evaluation of rifampicin-loaded poly lactideco-glycolide nanoparticles, Nanomedicine 3 (2007) 161-167; http://dx.doi.org/10.1016/j.nano.2007.03.003.

[2] E. Imbuluzqueta, E. Elizondo, C. Gamazo, E. Moreno-Calvo, J. Veciana, N. Ventosa, M. J. Blanco-Prieto, Novel bioactive hydrophobic gentamicin carriers for the treatment of intracellular bacterial infections, Acta Biomater 7 (2011) 1599-1608; https://doi.org/10.1016/j.actbio.2010.11.031

[3] S. Ravi, K. K. Peh, Darwis Y, B. K. Murthy, T. R. R. Singh, C. Mallikarjun, Development and characterization of polymeric microspheres for controlled release protein loaded drug delivery system, Indian Journal of Pharmaceutical Sciences, 70 (2008) 303.

[4] J. M. Anderson, M. S. Shive, Biodegradation and biocompatibility of PLA and PLGA microspheres. Advanced Drug Delivery Reviews 28 (1997) 5-24.

[5] J. Rotta, P.D. Pham, V. Lapinte, R. Borsali, E. Minatti, J. J. Robin, Synthesis of amphiphilic polymers based on fatty acids and glycerol-derived monomers - a study of their self-assembly in water, Macromolecular Chemistry and Physics 215 (2014) 131-139.

http://dx.doi.org/10.1002/macp.201300483.

[6] A. Bahrami, R. Delshadi, E. Assadpour, S. M. Jafari, L. Williams, Antimicrobial-loaded nanocarriers for food packaging applications, Advances in Colloid and Interface Science 278 (2020) 102140.

[7] J. B. E. Mendes, M. K. Riekes, V. M. De Oliveira, M.D. Michel, H. K. Stulzer, N. M. Khalil, S. F. Zawadzki, R. M. Mainardes, P. V. Farago, , PHBV/PCL microparticles for controlled release of resveratrol: physicochemical characterization, antioxidant potential, and effect on hemolysis of human erythrocytes. The Scientific World Journal 2012 (2012) 542937.

[8] C. Lecároz, M. J. Blanco-Prieto, M. A. Burrell, C. Gamazo, Intracellular killing of Brucellamelitensis in human macrophages with microsphere-encapsulated gentamicin, Journal of antimicrobial chemotherapy 58 (2006) 549-556, http://dx.doi.org/10.1093/jac/dkl257.

[9] M. C. Lecaroz, M. J. Blanco-Prieto, M. A. Campanero, H. Salman, C. Gamazo, Poly (D, L-lactidecoglycolide) particles containing gentamicin: pharmacokinetics and pharmacodynamics in Brucella melitensis-infected mice, Antimicrobial Agents and Chemotherapy 51 (2007) 1185. http://dx.doi.org/10.1128/AAC.00809-06 
[10] M. M. Amer, K. F. Takla, Studies on the stability of some pharmaceutical formulations: V Stability of erythromycin, Bulletin of the Faculty of Pharmacy Cairo University 15 (1976) 325-339.

[11] D. P. Gaspar, M. M. Gaspar, C. V. Eleutério, A. Grenha, M. Blanco, L. M. Gonçalves, P. Taboada, A. J. Almeida, C. Remuñan-López, Microencapsulated solid lipid nanoparticles as a hybrid platform for pulmonary antibiotic delivery, Molecular Pharmaceutics 14 (2017) 2977-2990.

https://doi.org/10.1021/acs.molpharmaceut.7b00169

[12] L. M. Blandón, G. A. Islan, G. R. Castro, M. D. Noseda, V. Thomaz-Soccol, C. R. Soccol, Kefiran-alginate gel microspheres for oral delivery of ciprofloxacin, Colloids and Surfaces B 145 (2016) 706-715; http://dx.doi.org/doi:10.1016/j.colsurfb.2016.05.078

[13] M. R. Prado, L. M. Blandón, L. P. Vandenberghe, C. Rodrigues, G. R. Castro, V. ThomazSoccol, C. R. Soccol, Milk kefir: composition, microbial cultures, biological activities, and related products, Frontiers in Microbiology 6 (2015) 1177.

http://dx.doi.org/10.3389/fmicb.2015.01177

[14] H. A. Almoustafa, M. A. Alshawsh, Z. Chik, Technical aspects of preparing PEG-PLGA nanoparticles as carrier for chemotherapeutic agents by nanoprecipitation method, International Journal of Pharmaceutics 533 (2017) 275-284.

http://dx.doi.org/10.1016/j.ijpharm.2017.09.054

[15] J. S. Ananta, R. Paulmurugan, T. F. Massoud, Temozolomide-loaded PLGA nanoparticles to treat glioblastoma cells: a biophysical and cell culture evaluation, Neurological Research, 38 (2016) 51-59. http://dx.doi.org/10.1080/01616412.2015.1133025

[16] M. Brisaert, M. Heylen, J. Plaizier-Vercammen, Investigation on the chemical stability of erythromycin in solutions using an optimization system, Pharmacy World and Science 18 (1996) 182186.

[17] K. Eljaaly, A. Botaish, F. Bahobail, M. Almehmadi, Z. Assabban, A. K. Thabit, B. Alraddadi, A. Aljabri, N. Alqahtani, M. A. Aseeri, A. Hashim, A. Torres, Systematic review and meta-analysis of the safety of erythromycin compared to clarithromycin in adults and adolescents with pneumonia, Journal of Chemotherapy 32 (2020) 1-6.

[18] D. Essa, P. P. Kondiah, Y. E. Choonara, V. Pillay, The design of poly (lactide-co-glycolide) nanocarriers for medical applications, Frontiers in Bioengineering and Biotechnology 8 (2020) 48. https://doi.org/10.3389/fbioe.2020.00048 
[19] L. Bennabi, H. W. Abiras, L. Belarbi, F. Bennabi, W. Chaibi, K. Guemra, Effect of polymer blends and evaluation from controlled release procaine $\mathrm{HCl}$ loaded poly ( $\varepsilon$-caprolactone) microsphers, Biointerface Research in Applied Chemistry 6 .Issue 5(2016)1483-1490. 


\section{Figures}

(a)

Base(112)

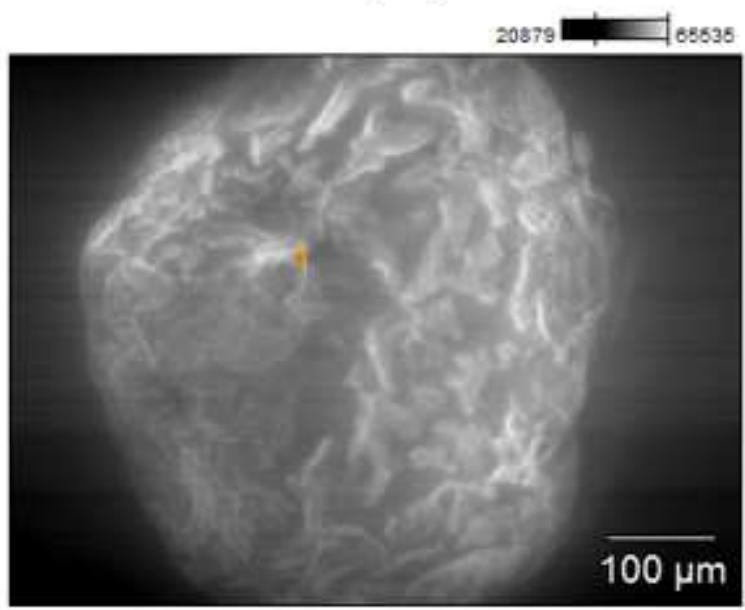

(b)

Base(107)

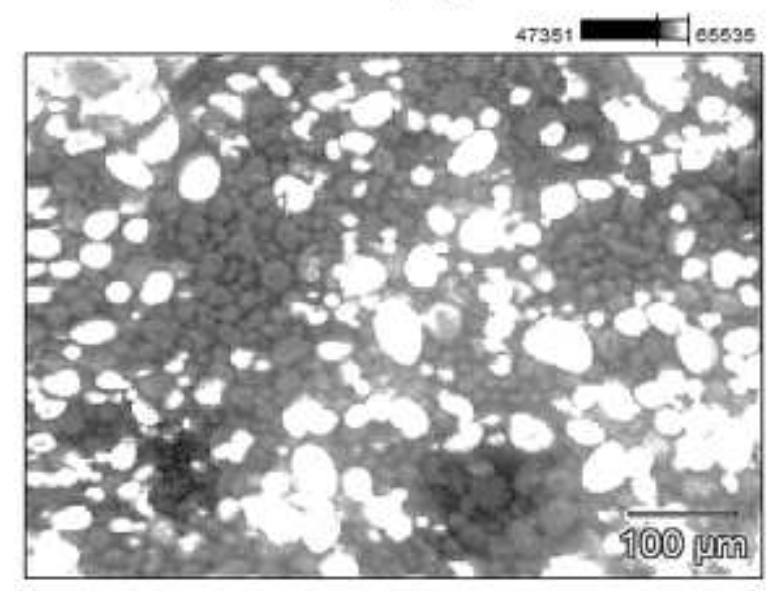

Figure 1

SEM micrographs: (a) A1 and (b) A2 microspheres.

(a)

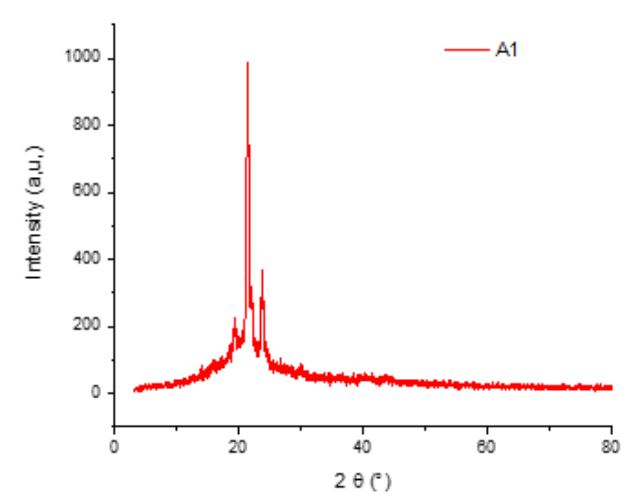

(b)

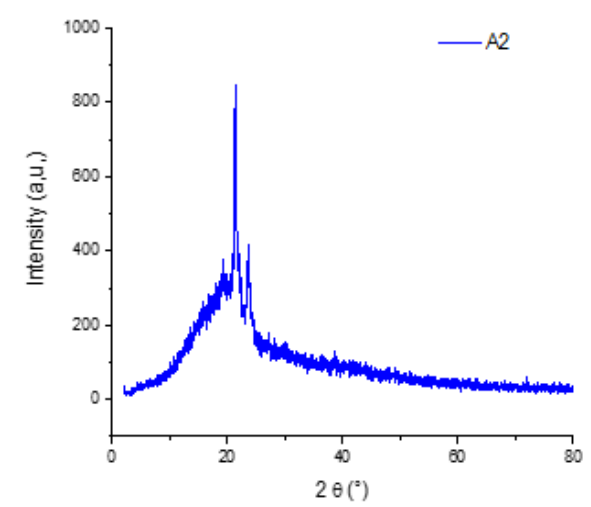

(c)

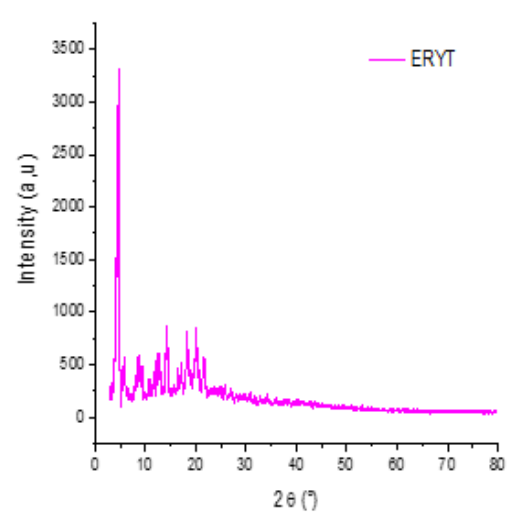

Figure 2

XDRpatterns: (a) A1 microspheres,(b) A2 microspheres and (c) ERYT antibiotic. 
(a)

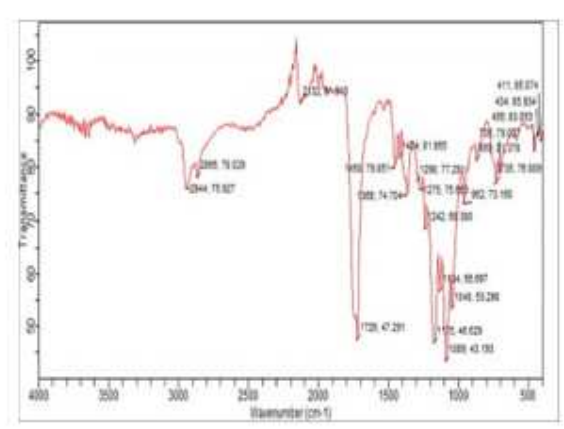

(b)

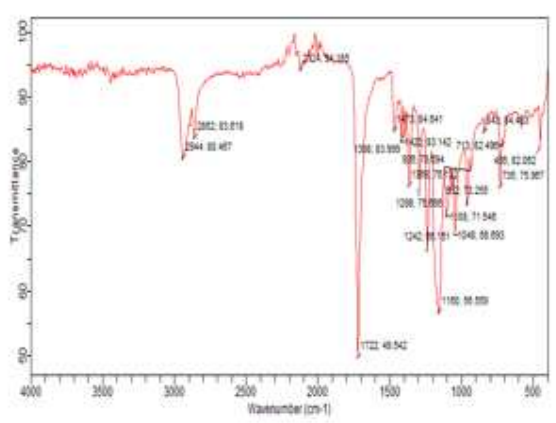

(c)

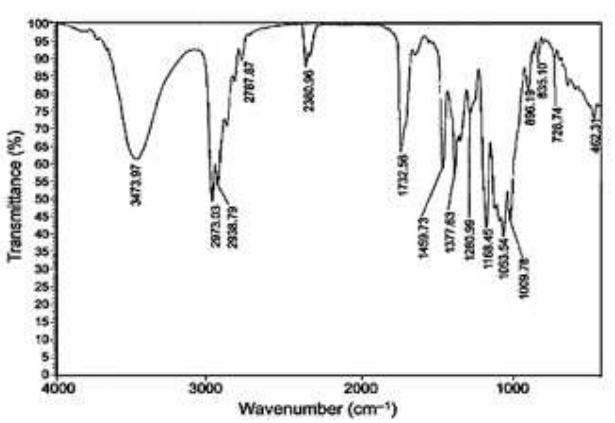

Figure 3

FTIR spectra:(a) A1 microspheres, (b) A2 microspheres and (c) ERYT antibiotic.

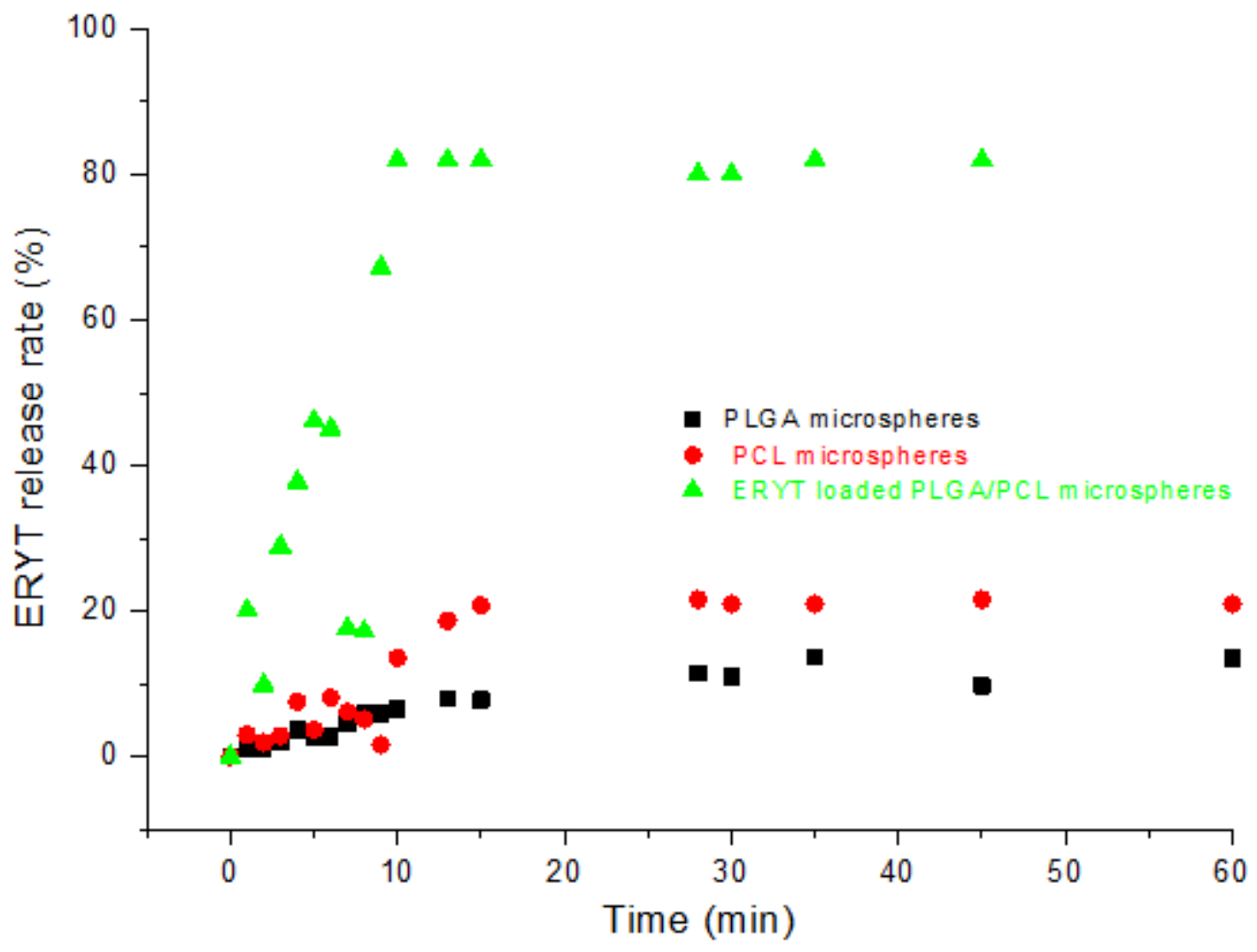

Figure 4

Release profiles of ERYT from A0.1, A0.2 and A2 microspheres. 
(a)

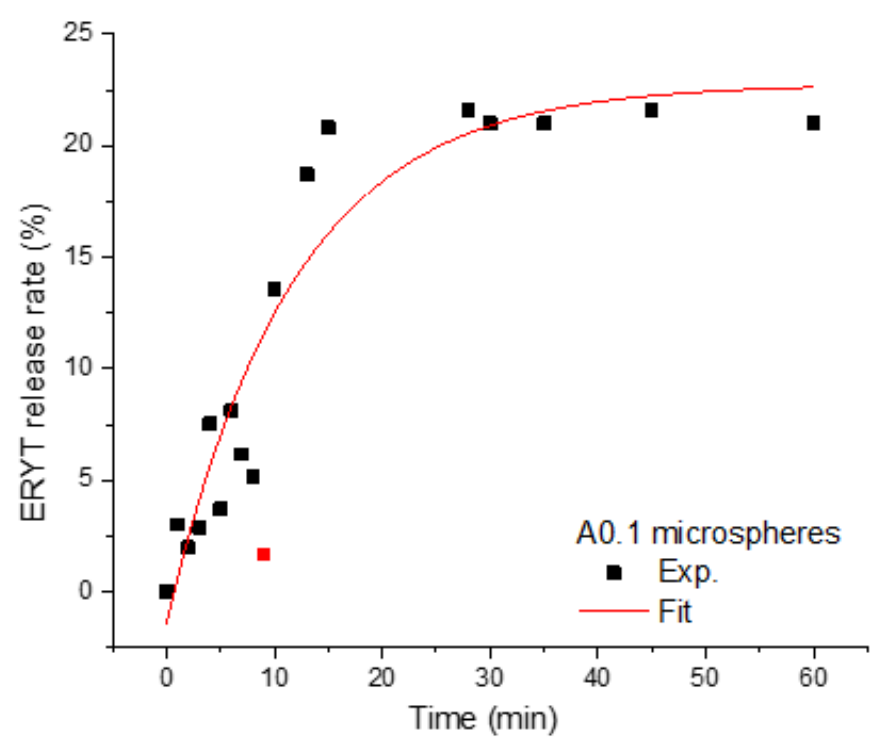

(b)

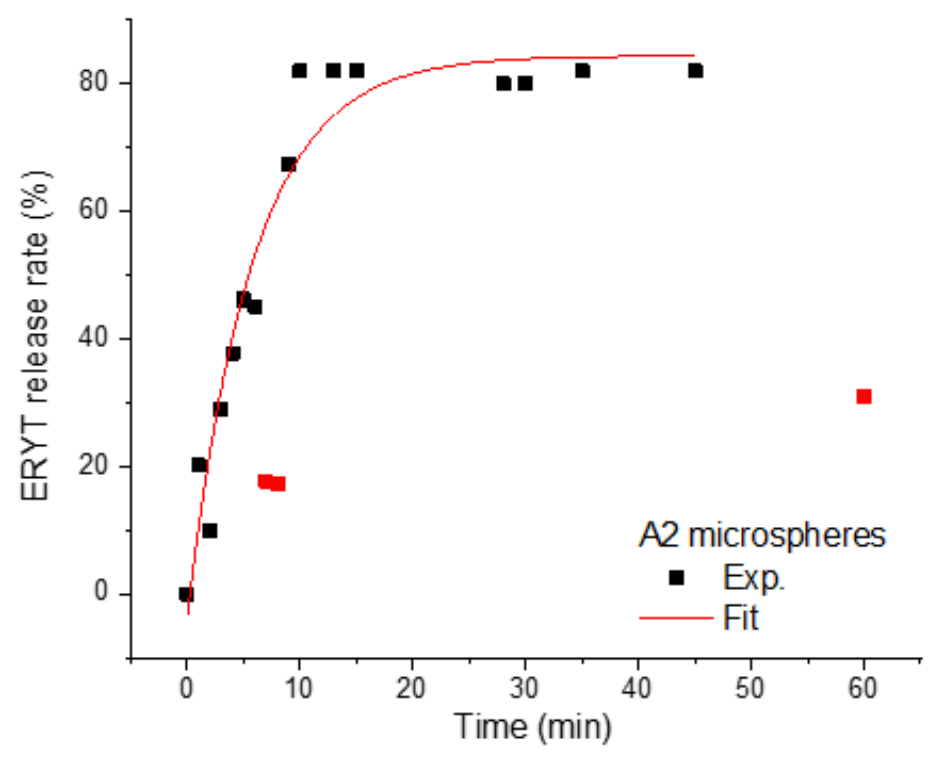

(c)

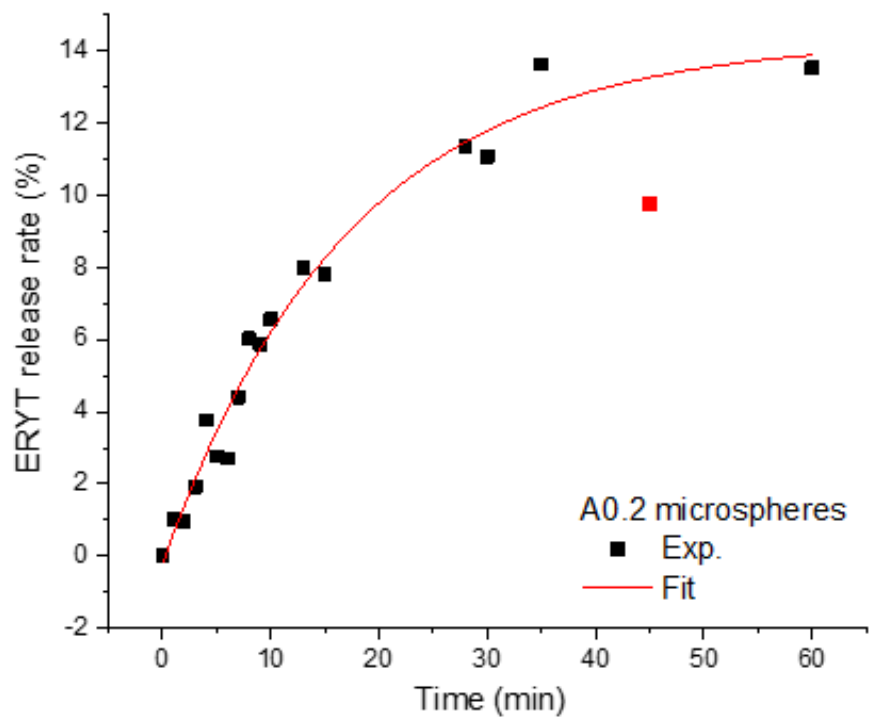

Figure 5

Mathematical modeling of ERYT release from A0.1,A0.2 and A2. 

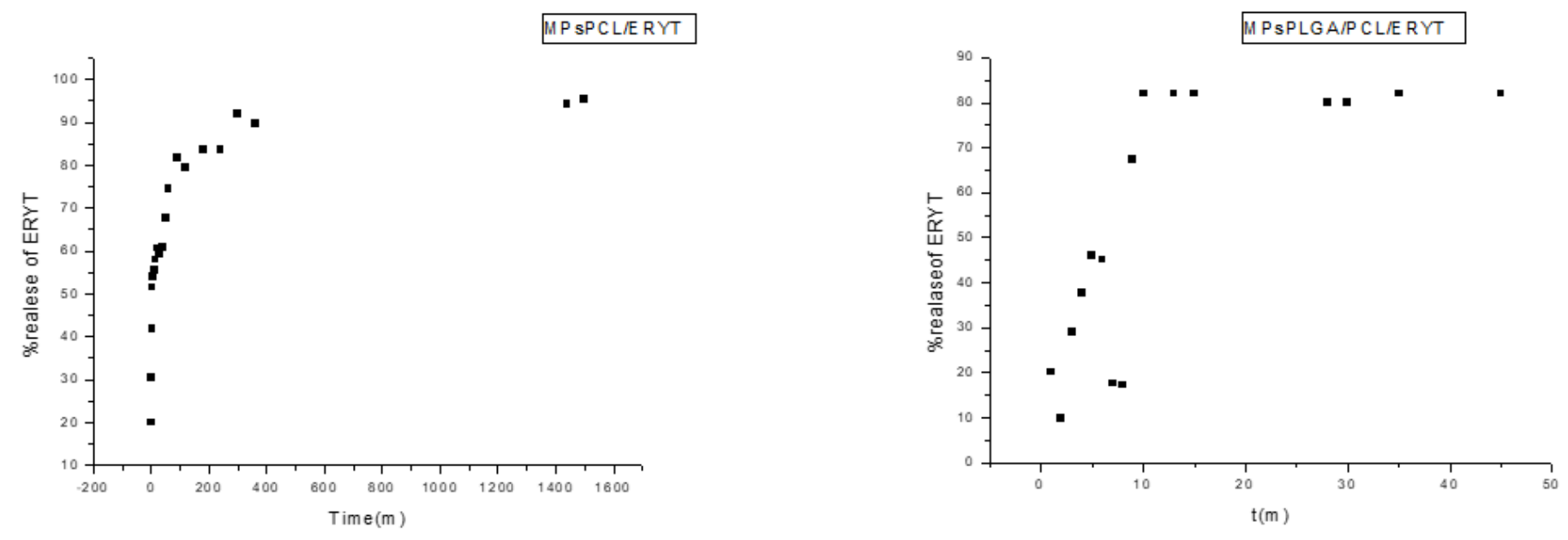

Figure 6

\% ERYT concentration from A1(a) and A2(b) microspheres

(a)

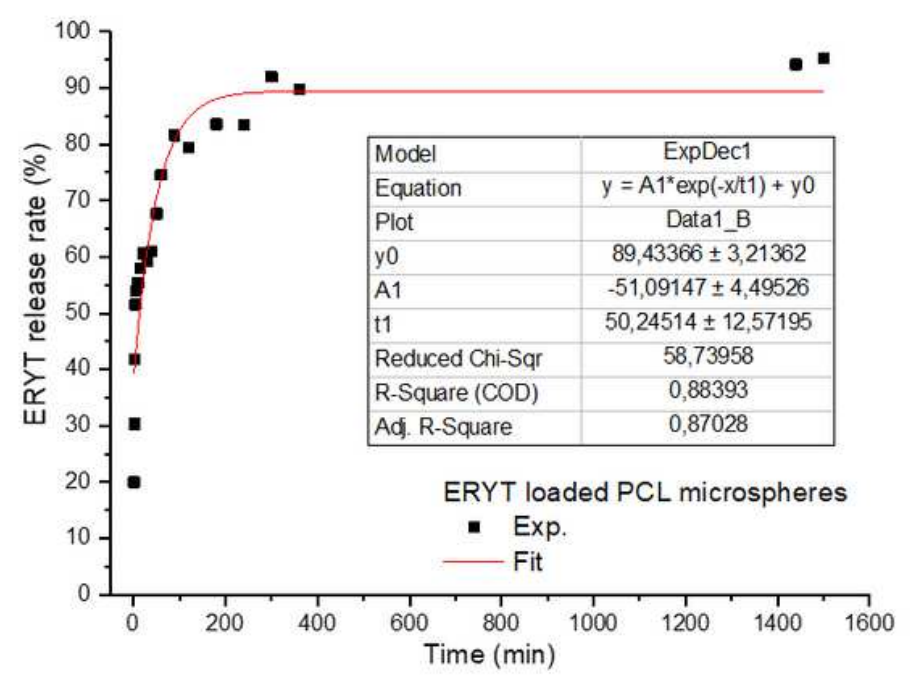

(b)

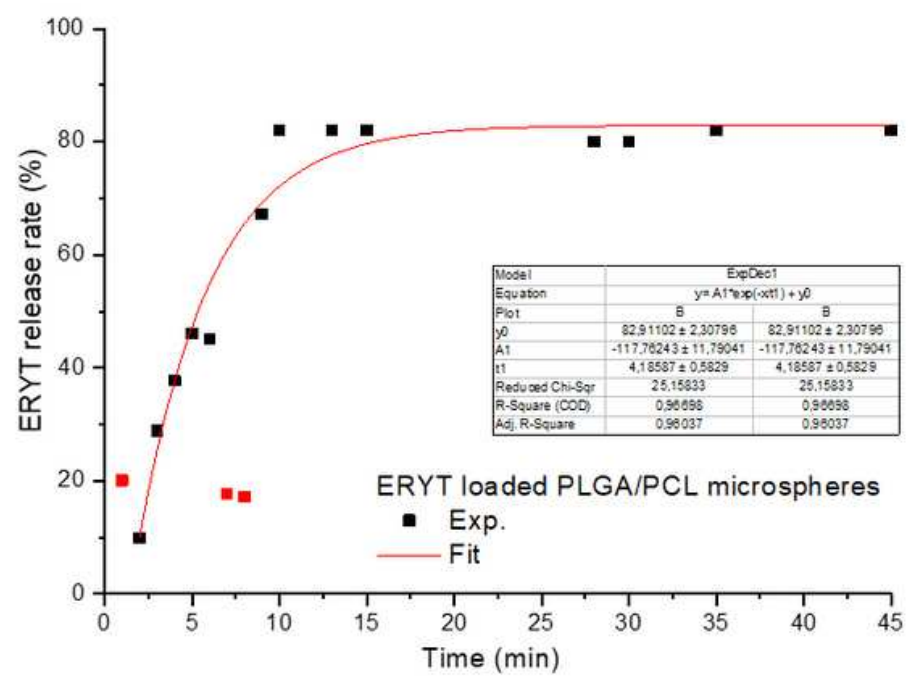

Figure 7

dissolution of ERYT from A1 (a) and A2 (b) microparticals in solution media(pH7.4) 
(a)

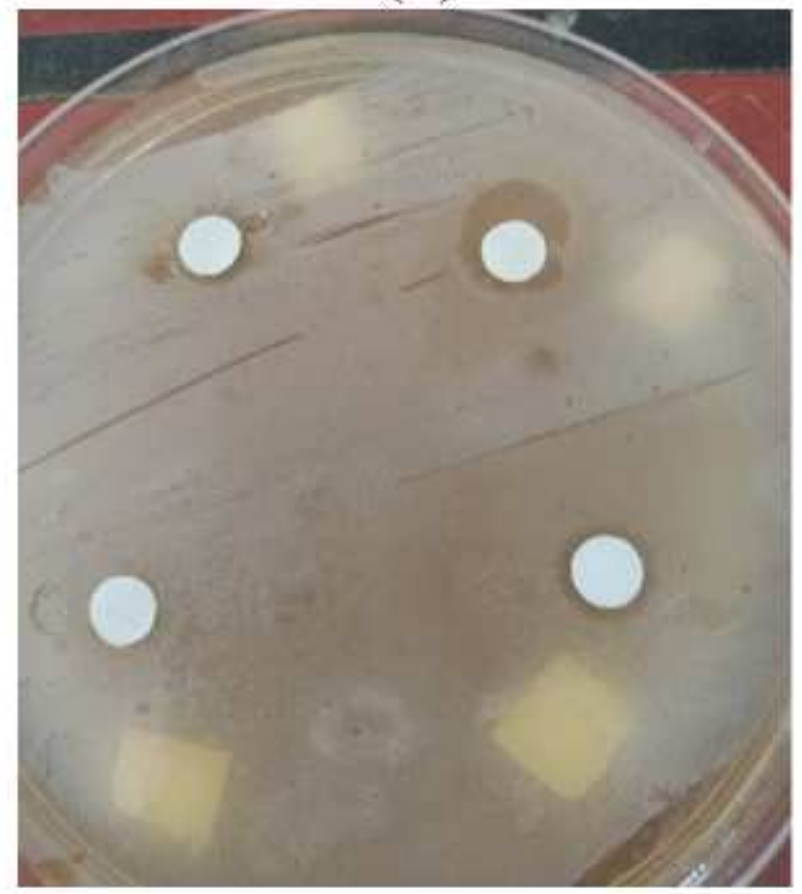

(b)

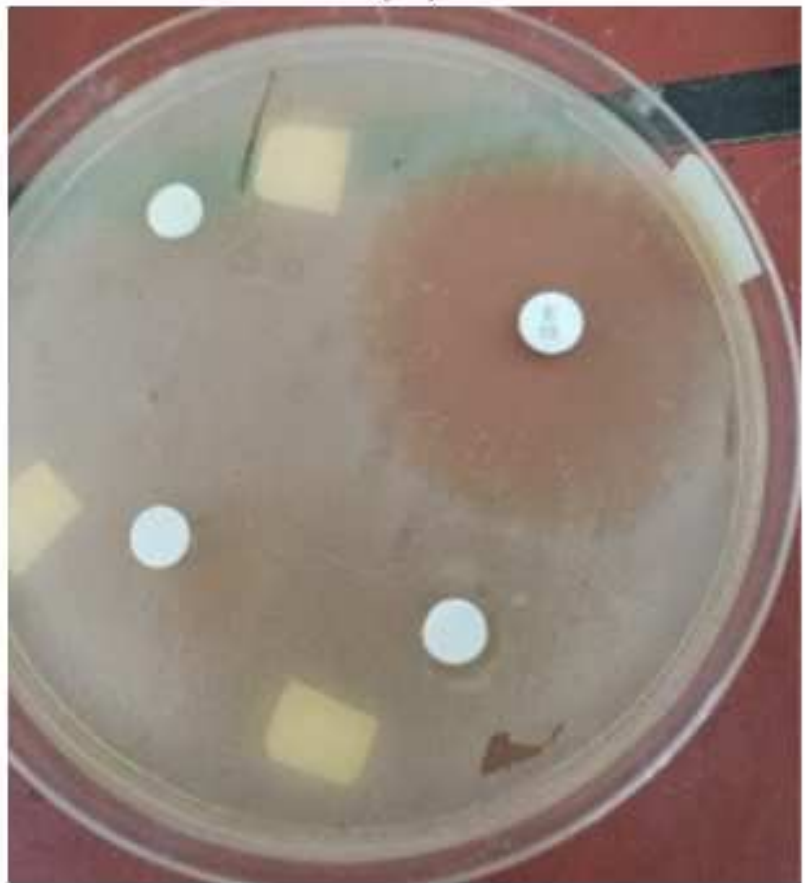

Figure 8

Micrographs of inhibition diameters of S aureus using A1 (a) and A2 (b) formulation. 


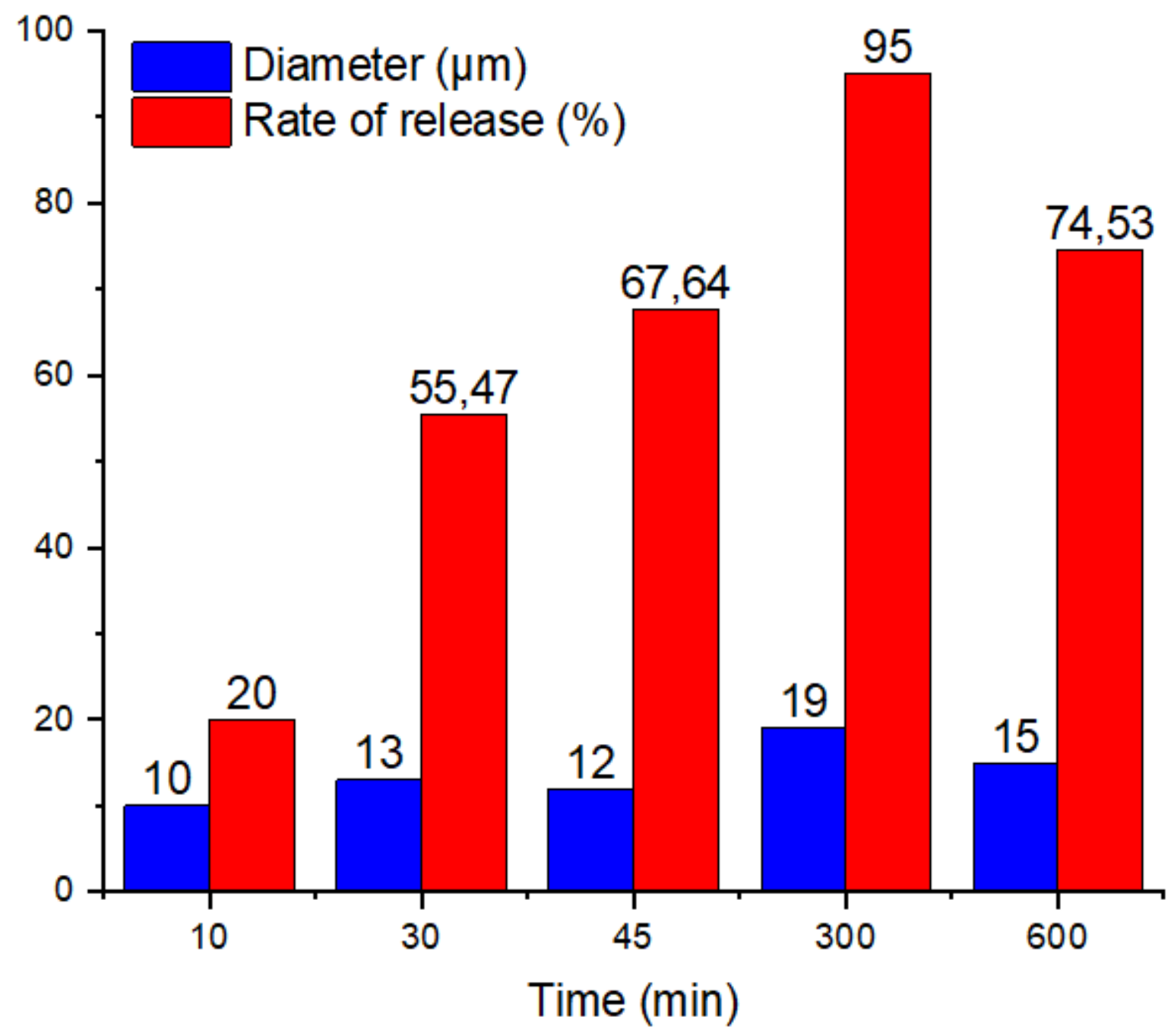

Figure 9

Variation of the diameter and the rate of release versus time for A1 formulation. 


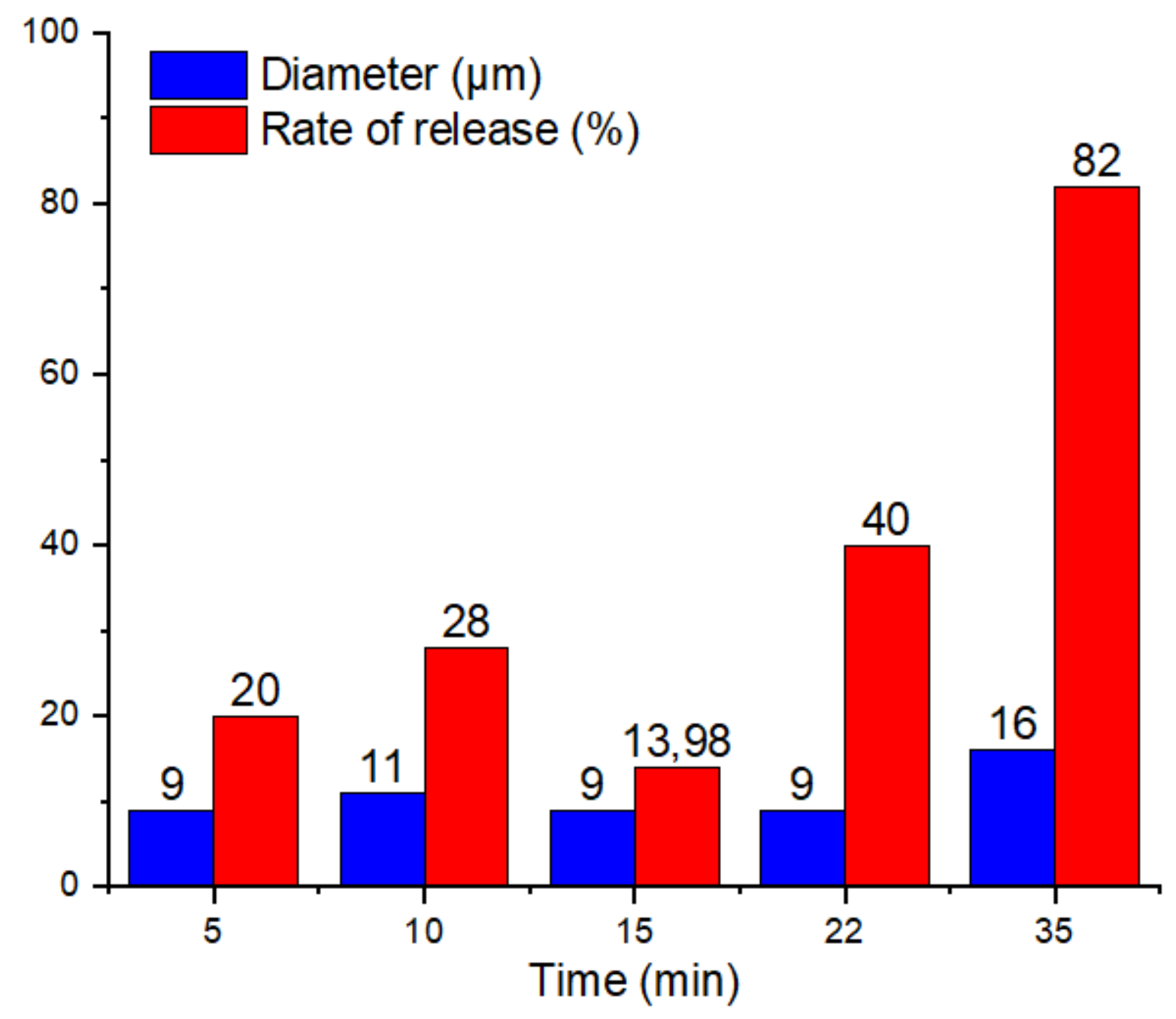

Figure 10

Variation of the diameter and the rate of release for A2formulation. 
(a)

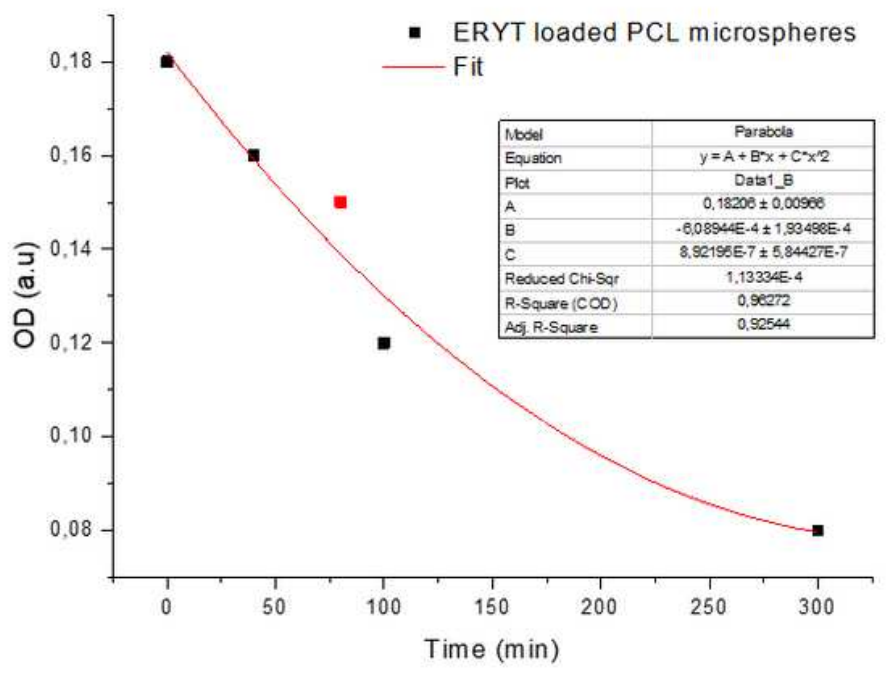

(b)



Figure 11

Variation of the absorbance of S. aureus inA1(b) and A2 (a)nanoparticles. 